\title{
Analytical model of workpiece temperature in axial ultrasonic vibration-assisted milling in-situ $\mathrm{TiB}_{2} / 7050 \mathrm{Al}$ MMCs
}

\author{
Xiaofen Liu ( $\nabla$ xiaofl1987@mail.nwpu.edu.cn ) \\ Northwestern Polytechnical University \\ Wenhu Wang \\ Northwestern Polytechnical University \\ Ruisong Jiang \\ Northwestern Polytechnical University \\ Yifeng Xiong \\ Northwestern Polytechnical University \\ Kunyang Lin \\ Northwestern Polytechnical University \\ Junchen Li \\ Northwestern Polytechnical University \\ Chenwei Shan \\ Northwestern Polytechnical University
}

\section{Research Article}

Keywords: Ultrasonic vibration, Cutting temperature, Analytical model, In-situ, Al-MMCs

Posted Date: March 19th, 2021

DOI: https://doi.org/10.21203/rs.3.rs-320496/v1

License: (1) This work is licensed under a Creative Commons Attribution 4.0 International License. Read Full License

Version of Record: A version of this preprint was published at The International Journal of Advanced Manufacturing Technology on November 27th, 2021. See the published version at https://doi.org/10.1007/s00170-021-08105-z. 


\section{Abstract}

As a new method developed for machining difficult-to-cut materials, ultrasonic vibration-assisted machining technology has received increasing attention due to its superior properties in reducing cutting temperature in recent years. However, analytical models revealing the mechanism and predicting the cutting temperature for ultrasonic vibration-assisted machining are still needed to be developed. In this paper, an analytical model was established to predict the workpiece temperature for ultrasonic vibration-assisted milling of in-situ $\mathrm{TiB}_{2} / \mathrm{Al}-\mathrm{MMCs}$. The heat intensity would be directly determined by the cutting force which was significantly influenced by the ultrasonic vibration motion. Meanwhile, the moving heat source theory was applied for calculating dynamic heat flux and partition ratio. Besides, material properties, tool geometry, cutting parameters and vibration parameters were taken into account for workpiece temperature modeling. Finally, the developed analytical temperature model was validated by milling experiments with and without ultrasonic vibration on in-situ $\mathrm{TiB}_{2} / 7050 \mathrm{Al}$ metal matrix composites. The relative errors between model prediction results and experiments were smaller than $17 \%$, indicating that the proposed model could provide workpiece temperature prediction reliability and accuracy. Furthermore, the established-analytical model could be used not only in ultrasonic vibration-assisted milling but also in conventional milling for the metal matrix composites.

\section{Introduction}

The heat generated in metal cutting process resulting in cutting temperature rising is one of the main physical phenomena, which would have a direct significant effect on the surface quality, residual stress and machined defects in metal removal processes. In decades, the ultrasonic vibration-assisted machining technology has been applied in aviation industry as an effective method for machining difficult-to-cut materials due to its superior advantages in reducing cutting force [1-3], decreasing cutting temperature [4] and improving surface integrity $[5,6]$. Compared with conventional machining method, the motion of cutting tool or workpiece and the material removal process is changed in ultrasonic vibration-assisted machining, which would result in great difference in cutting temperature generation and its effects on machining quality. Therefore, to have a better understanding of cutting temperature in ultrasonic vibration-assisted machining, experimental and analytical modeling researches are quite necessary.

Li et al. [7] conducted an experimental study on rotary ultrasonic drilling Ti6Al4V alloy, it was found that the cutting temperature was reduced by $18.54 \% \sim 21.68 \%$ compared with conventional drilling process. Geng et al. [8] studied the influence of cutting parameters on cutting temperature during elliptical ultrasonic vibration cutting carbon fiber-reinforced polymer (CFRP) composites. The results indicated that the cutting temperature was obviously reduced by ultrasonic vibration cutting and the feed velocity had more significant influence on cutting temperature than cutting velocity. Cong et al. [9] carried out experimental investigation on the effect of cutting parameters and ultrasonic parameters on cutting temperature in rotary ultrasonic assisted machining CFRP. The results showed that the feed rate had the highest effect on cutting temperature. However, the researches of Pálmai [10] and Stephenson et al. [11], it was found that the cutting velocity was the main factor influencing the cutting temperature. Shi et al. [12] concluded from elliptical ultrasonic cutting 
Ti6Al4V/Al7050 alloy, that the vibration frequency was the major factor influencing cutting force and the vibration amplitude was the main factor influencing cutting temperature.

Meanwhile, with increasing development of computer technology, the finite element method based on simulation software was also applied to have an insight of ultrasonic vibration-assisted machining process and cutting temperature generation process. Mitrofanov et al. $[13,14]$ proposed a thermo-mechanical coupled finite element (FE) models for conventional turning (CT) and ultrasonic assisted turning (UAT) Inconel 718. It was found that the cutting tool temperature in UAT was about 2 times lower than that in CT. However, temperature of cutting region in UAT was found to be $15 \%$ higher than that in CT, which came to the same conclusion by Ahmed et al [15]. Besides, there was no considerable differences in workpiece temperature between the two cutting methods. For this, Muhammad et al. [16] explained that it needed to consume energy due to the ultrasonic shock, which would result in the temperature in the cutting zone increasing. Patil et al. [17] conducted comparative investigation on Ti6Al4V alloy between CT and UAT methods. It was noted that cutting temperature was reduced by UAT and with increasing from $10 \mathrm{~m} / \mathrm{min}$ to $30 \mathrm{~m} / \mathrm{min}$ the differences between the max cutting temperature in UAT and CT was reduced from $48-16 \%$.

To fully address the cutting temperature generation in ultrasonic vibration-assisted machining process, analytical mathematical modeling effort has been made. Khajehzadeh et al. [18] developed an average temperature prediction model for the cutting tool in UAT and proposed a cutting velocity model by considering kinematics of cutting process. However, the model building depended on conducting experiments to obtain tool-chip contact lengths of sticking and slipping. Verma et al. [19] proposed an analytical model for temperature rise in workpiece during ultrasonic vibration-assisted milling (UVM). It considered the effect of acoustic softening and intermittent cutting based on Jaeger's moving heat source theory. The model showed good agreement with experimental results. Chen et al. [20] developed a non-uniform moving heat source model to analyze the heat transfer problem in ultrasonic assisted cutting Ti6Al4V. The results indicated that the temperature in the machined surface was lower with larger vibration amplitude, while the surface temperature increased with vibration frequency increasing.

From above, although the cutting temperature in ultrasonic vibration-assisted machining has been researched from experiments, simulation to modeling, there is still a few attempts for analytical temperature modeling of workpiece in ultrasonic vibration-assisted milling process. Furthermore, ultrasonic vibration-assisted machining method has shown advantages in reducing tool wear and cutting force, improving machining quality in cutting in-situ $\mathrm{TiB}_{2} / 7050 \mathrm{Al}$ composites which is a typical difficult-to-cut material [21-24]. Hence, it is quite necessary and important to perform temperature modeling investigation for ultrasonic vibrationassisted milling in-situ $\mathrm{TiB}_{2} / 7050 \mathrm{Al}$ composites for fully and comprehensively understanding the influence of ultrasonic vibration on machining quality.

Therefore, in this paper, an analytical model of workpiece temperature was proposed in ultrasonic vibrationassisted milling in-situ $\mathrm{TiB}_{2} / 7050 \mathrm{Al}$ composites. Firstly, a cutting force model was developed by analyzing the coupled effect of tool-chip-workpiece and inertial force with considering ultrasonic vibration motion. Based on the heat source theory and cutting theory, the dynamic heat density and the heat partition ratio was analyzed and calculated. Then, the geometry of the cutting tool and processing parameters were taken into 
consideration to establish the temperature model. Finally, the proposed model is validated by a series of milling experiments with and without ultrasonic vibration on in-situ $\mathrm{TiB}_{2} / 7050 \mathrm{Al}$ composites.

\section{Cutting Temperature Modeling 2.1. Cutting force model}

As sinusoidal vibration imposed on the cutting tool, the axial ultrasonic vibration-assisted milling (UVM) differs greatly from conventional milling. As described as Fig. 1, the cutting tool vibrates with high frequency and low amplitude during UVM process, the motion of tool is changed. Cutting force in UVM is different from that in $\mathrm{CM}$, which has significant influence on cutting temperature.

Cutting force generation and predication in UVM was analyzed in Ref. [25], which could provide cutting force data for temperature modeling. According to Ref. [25], the cutting force model was given out as following:

$$
\left\{\begin{array}{c}
F_{X}(t)=\sum_{j=1}^{r} \sum_{k=1}^{N}\left(-F_{\mathrm{t}(j, k)} \cos \theta_{j, k}(t)-F_{\mathrm{r}(j, k)} \sin \theta_{j, k}(t)\right) \\
F_{y}(t)=\sum_{j=1}^{r} \sum_{k=1}^{N}\left(F_{\mathrm{t}(j, k)} \sin \theta_{j, k}(t)-F_{\mathrm{r}(j, k)} \cos \theta_{j, k}(t)\right) \\
F_{z}(t)=\frac{1}{2} R \sum_{\mathrm{c}}^{r} \sum_{j=1}^{r} \sum_{k=1}^{N} F_{a(j, k)}
\end{array}\right.
$$

where $F_{\mathrm{t}(j, k)}, F_{\mathrm{r}(j, k)}$ and $F_{\mathrm{a}(j, k)}$ are tangential, radial and axial components of cutting force of the $k$ th flute. $\theta_{j, k}(t)$ is the angular position of the cutting point of the $j$ th slice in the $k$ th flute. The index of the slices $j=1,2,3, \cdots, r$, where $r$ is the number of the slices. The index of the flutes $k=1,2,3, \cdots, N$, where $N$ is the number of the teeth of milling tool, $R_{\mathrm{c}}$ refers to the cutting tool-workpiece contact rate [26] and its coefficient 1/2 means that the cutting tool-workpiece contact time was half vibration period.

\subsection{Analysis of heat source}

In metal cutting process, most of the energy generated in the primary deformation zone, secondary deformation zone and tertiary deformation zone is converted into thermal energy. As presented in Fig. 2 , in the primary deformation zone, heat is generated due to the plastic deformation of the workpiece and named shear heat source. In secondary deformation zone, heat is created due to the deformation of chip and the toolchip interface friction, which is called the frictional heat source. And in tertiary deformation zone, heat produced by tool-workpiece interface rubbing, which is the rubbing heat source.

Generally, most of heat generated by frictional heat source is transformed into cutting tool and chips [27], which has a bit influence on the workpiece temperature [28]. The effect of the rubbing heat source on toolworkpiece interface is minimum, which is determined greatly by tool wear. Then in this study, the cutting tool was assumed no tool wear and the influence of the rubbing heat source on the workpiece was considered to be negligible. Meanwhile, compared to the heat transferred into workpiece, the heat partition escaping to atmosphere through the boundary could be ignored, meaning that interfaces of tool-workpiece, tool-chip, workpiece-air, chip-air and tool-air could all be treated as adiabatic. 
Hence, in this paper, workpiece temperature rising was assumed to be mainly caused by the shear heat source. Then based on Komanduri-Hou's model [29], the heat liberation intensity of the shear heat source could be given as follow:

$q_{\text {shear }}=\frac{F_{\mathrm{s}} V_{\mathrm{s}}}{L b}$

where $F_{\mathrm{s}}$ is the shear force, $v_{\mathrm{s}}$ is the shear velocity, $L$ is the length of the shear plane, $b$ is the cutting width in the orthogonal cutting.

\subsection{Temperature model and heat partition ratio}

During UVM process, a new machined surface is formed mainly by the interaction between the bottom cutting edge and the workpiece. In spite of the ultrasonic vibration, Verma et al. [26] pointed out that $v$ could be considered as the average cutting velocity for describing the cutting speed of the tool. According to Xiong [30], the cutting process of the bottom cutting edge could be equivalent to the orthogonal cutting. However, the cutting speed is different along the bottom cutting edge direction. To address this, the bottom cutting edge is discretized into several elements and every element $d$ / could be regarded as a typical orthogonal cutting process as shown in Fig. 3 (a).

Moreover, it is assumed that the heat distribution is uniform near the shear plane which is treated as a semiinfinite medium. In order to describe the heat transfer practically, an imaginary shear heat source is introduced as shown in Fig. 3 (b). Therefore, the temperature rise in workpiece is mainly caused by the shear heat source and its imaginary heat source. Then the temperature of a point $M_{(x, y, z)}$ in workpiece could be expressed with combining effect of the shear heat source and its imaginary heat source as follow:

$$
T_{\mathrm{M}(x, y, z)}=T_{\mathrm{M}(x, y, z)}^{\text {shear }}+\underset{\mathrm{M}(x, y, z)}{\text { image }-\mathrm{s}}
$$

where $T_{\mathrm{M}(x, y, z)}^{\text {shear }}$ is the temperature caused by the shear plane heat source, $T_{\mathrm{M}(x, y, z)}^{\text {image }-\mathrm{s}}$ is the temperature effected by the imaginary shear heat source.

In order to obtain the temperature model and the heat partition ratio, two local coordinate systems $X_{t} O_{t} Z_{t}$ and $X_{\mathrm{c}} \mathrm{O}_{\mathrm{c}} Z_{\mathrm{c}}$ are built to analyze the cutting temperature on the workpiece side and on the chip side, which are shown in Fig. 4 (a) and Fig. 4 (b) respectively.

According to Komanduri and Hou [29], the cutting temperature $T_{\text {workpiece-shear }}$ caused by the shear heat source and the imaginary heat source for point $M_{\mathrm{t}}\left(x_{\mathrm{t}}, z_{\mathrm{t}}\right)$ on the workpiece side could be calculated as follow: 


$$
\left\{\begin{array}{l}
T_{\text {workpiece }- \text { shear }}=\frac{B_{\mathrm{s}} q_{\text {shear }}}{2 \Pi \lambda_{W}} \int_{0}^{L} e^{-\left(x_{\mathrm{t}}-l_{i} \cos \varphi\right) v_{\mathrm{e}}{ }^{2} / 2 a_{\mathrm{w}} \times K_{0}^{s h e a r} \frac{v_{\mathrm{e}}^{2}}{2 a_{\mathrm{w}}}\left(R_{\mathrm{t} 1}+R_{\mathrm{t} 2}\right) d l_{i}} \\
R_{\mathrm{t} 1}=\sqrt{\left(x_{\mathrm{t}}-l_{i} \cos \varphi\right)^{2}+\left(z_{\mathrm{t}}+l_{i} \sin \varphi\right)^{2}} \\
R_{\mathrm{t} 2}=\sqrt{\left(x_{\mathrm{t}}-l_{i} \cos \varphi\right)^{2}+\left(2 t_{\mathrm{c}}+z_{\mathrm{t}}-l_{i} \sin \varphi\right)^{2}}
\end{array}\right.
$$

where $B_{\mathrm{S}}$ stands for the fraction of the shear heat source conducted into the workpiece, $\lambda_{\mathrm{w}}$ is the thermal conductivity of the workpiece, $a_{\mathrm{w}}$ is the thermal diffusion coefficient of the workpiece, and $\mathrm{K}_{0}^{\text {shear }}$ denotes the modified Bessel function of second kind of order zero, $t_{c}$ is uncut chip thickness, $\phi$ is shear angle [30], $v_{\mathrm{e}}$ is the instantaneous velocity of a point on cutting edge, $q_{\text {shear }}$ is the heat liberation intensity of the shear heat source, they could be calculated as following:

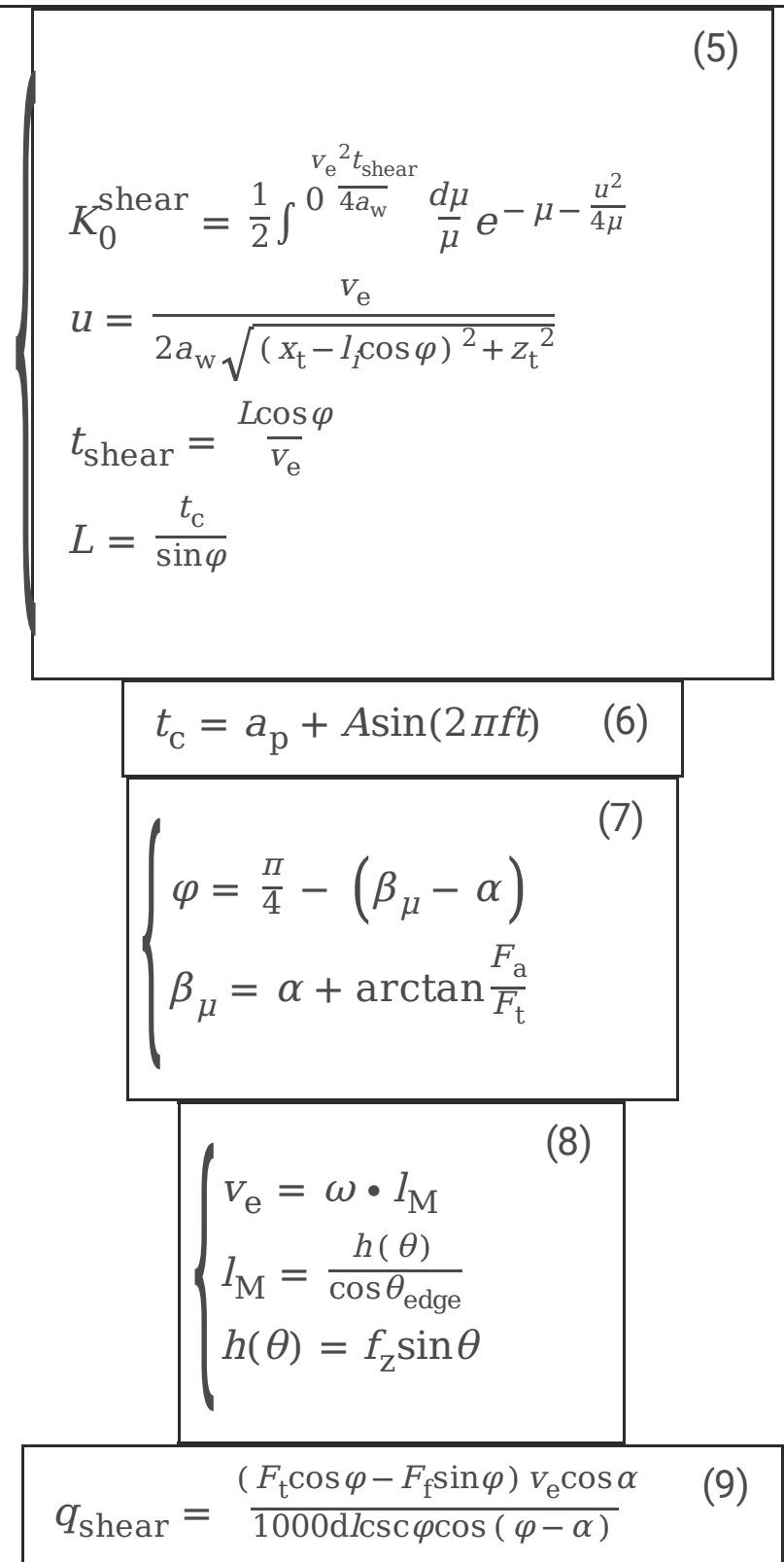

where $f$ is vibration frequency, $A$ is vibration amplitude, $a_{\mathrm{p}}$ is cutting depth, $\beta_{\mu}$ is frictional angle [31], $a$ is the rake angle of the cutting tool, $I_{M}$ is the actual length of the bottom edge involved in cutting, $h(\theta)$ is the 
instantaneous cutting thickness, $\theta_{\text {edge }}$ is the inclination angle of the bottom edge, $f_{\mathrm{z}}$ is feed rate, $\theta$ is instantaneous immersion angle, $F_{\mathrm{t}}, F_{\mathrm{a}}$ and $F_{f}$ is the tangential cutting force, axial cutting force and thrust force in the orthogonal cutting process respectively.

Then, the cutting temperature $T_{\text {chip-shear }}$ produced by the shear heat source and the imaginary heat source on the chip side at the point $M_{\mathrm{c}}\left(x_{\mathrm{c}}, z_{\mathrm{C}}\right)$ could be expressed as follow:

$$
\left\{\begin{array}{l}
T_{\text {chip - shear }}=\frac{\left(1-B_{\mathrm{s}}\right) q_{\mathrm{shear}}}{2 \pi \lambda_{\mathrm{ch}}} \int_{0}^{L} e^{-\left(x_{\mathrm{C}}-L_{\mathrm{C}}+l_{i} \sin (\varphi-\alpha)\right) v_{\mathrm{ch}}^{M_{\mathrm{c}}} / 2 a_{\mathrm{ch}} \times K_{0}^{\text {shear }} \frac{V_{\mathrm{ch}}^{M_{\mathrm{C}}}}{2 a_{\mathrm{ch}}}\left(R_{\mathrm{C} 1}+R_{\mathrm{C} 2}\right) d l_{i}} \\
R_{\mathrm{C} 1}=\sqrt{\left(x_{\mathrm{C}}-L_{\mathrm{C}}+l_{i} \sin (\varphi-\alpha)\right)^{2}+\left(z_{\mathrm{C}}-l_{i} \cos (\varphi-\alpha)\right)^{2}} \\
R_{\mathrm{C} 2}=\sqrt{\left(x_{\mathrm{C}}-L_{\mathrm{C}}+l_{i} \sin (\varphi-\alpha)\right)^{2}+\left(z_{\mathrm{C}}+2 t_{\mathrm{ch}}-l_{i} \cos (\varphi-\alpha)\right)^{2}}
\end{array}\right.
$$

where $\lambda_{\mathrm{ch}}$ is the thermal conductivity of the chip, $a_{\mathrm{ch}}$ is the thermal diffusion coefficient of the chip, $V_{\mathrm{ch}}^{M_{\mathrm{c}}}$ stands for the flow velocity of the chip, $t_{c h}$ is the thickness of the chip [32], $L_{c}$ is the contact length of tool-chip, they could be expressed as below:

$$
\left\{\begin{array}{l}
M_{\mathrm{C}}=\frac{\sin \varphi}{\cos (\varphi-\alpha)} V_{\mathrm{e}} \\
V_{\mathrm{ch}}=\left(t_{\mathrm{C}}+3 A\right)^{\sin \left(\frac{\pi}{2}-(\varphi-\alpha)\right)} \\
t_{\mathrm{ch}} \frac{t_{\mathrm{C}} \sin \left(\varphi+\beta_{\mu}-\alpha\right)}{\sin \varphi \cos \beta_{\mu}} \\
L_{\mathrm{C}}={ }^{\frac{\sin }{21)}}
\end{array}\right.
$$

According to Block's Partition Principle [33], $T_{\text {workpiece-shear }}$ and $T_{\text {chip-shear }}$ are merely two different expressions for the mean temperature rise at shear plane. Hence, $T_{\text {workpiece-shear }}$ and $T_{\text {chip-shear }}$ are equal in amount, which could be expressed as follow:

$$
T_{\text {workpiec-shear }}=T_{\text {chip }- \text { shear }}
$$

Thus, the heat partition ratio $B_{\mathrm{s}}$ could be obtained as follow:

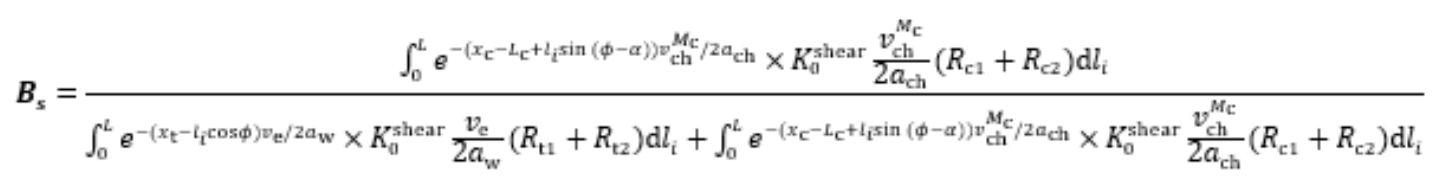

Finally, the workpiece temperature rise could be calculated by substituting the value of $B_{\mathrm{s}}$ in equation (4).

\subsection{Prediction of temperature in workpiece}


In this study, the cutting temperature rise by shear heat source is obtained through analyzing the temperature field of the orthogonal cutting process. UVM is a complicated 3D cutting process and it is quite necessary to consider the effect of tool geometry and cutting parameters. Besides, the cutting temperature is significantly determined by the cutting force calculated with Eq. (2). Then, in order to obtain the temperature rise of an arbitrary point $M(x, y, z)$ in the workpiece, a coordinate transformation from $x y z$ to $x_{t} y_{t} z_{t}$ is needed as following:

$\left[\begin{array}{l}x_{t} \\ y_{t} \\ z_{t} \\ 1\end{array}\right]=\left[\begin{array}{cccc}\cos \theta_{j, k}(t) & 0 & -\sin \theta_{j, k}(t) & 0 \\ 0 & 1 & 0 & 0 \\ \sin \theta_{j, k}(t) & 0 & \cos \theta_{j, k}(t) & 0 \\ 0 & 0 & 0 & 1\end{array}\right]\left[\begin{array}{l}x \\ y \\ z \\ 1\end{array}\right]+\left[\begin{array}{c}-R \sin \theta_{j, k}(t) \\ 0 \\ R\left(\cos \theta_{j, k}(t)-1\right) \\ 0\end{array}\right] \quad(14)$

At last, the cutting temperature could be calculated by equations (4). Due to a lot of complicated computation, the software MATLAB is used to write a program for this job and the programming, the flowchart is shown in Fig. 5.

\section{Experimental Design}

In order to validate the cutting temperature model, a set of down milling experiments were performed on the material of $6 \mathrm{wt} \%$ in-situ $\mathrm{TiB}_{2} / 7050 \mathrm{Al}$ MMCs, whose mechanical and physical properties of the material were shown in Table 1. The size of specimen used for milling tests was $40 \times 30 \times 8 \mathrm{~mm}$. The cutting tools used were TiAIN coated carbide end milling tools with diameter of $7 \mathrm{~mm}$ and 4 flutes, whose specifications were shown in Table 2.

Table 1

Mechanical and physical properties of TiB2/7050Al MMCs

\begin{tabular}{|llllll|}
\hline Density & $\begin{array}{l}\text { Yield } \\
\text { Strength } \\
\left(\mathbf{g} / \mathrm{cm}^{3}\right)\end{array}$ & $\begin{array}{l}\text { thermal } \\
\text { conductivity } \\
(\mathrm{MPa})\end{array}$ & $\begin{array}{l}\text { thermal diffusion coefficient } \\
(\mathrm{(m} /(\mathbf{m} \cdot \mathrm{K}))\end{array}$ & $\begin{array}{l}\text { Specific } \\
\text { heat }\end{array}$ & $\begin{array}{l}\text { Melt } \\
\text { temperature }\end{array}$ \\
\hline 2.9 & 630 & 112 & 0.451 & 78 & 476 \\
\hline
\end{tabular}

Table 2

Specifications of coated carbide milling tool

\begin{tabular}{|llllll|}
\hline Diameter & Rank angle & Nose radius & Flank angle & Helix angle & Tooth \\
\hline $7 \mathrm{~mm}$ & $5^{\circ}$ & $0.2 \mathrm{~mm}$ & $8^{\circ}$ & $40^{\circ}$ & 4 \\
\hline
\end{tabular}


All experiments were done on a CY-VMC850 machine with and without ultrasonic vibration under dry machining condition as shown in Fig. 6.

The whole experimental setup is mainly composed of three parts including ultrasonic vibration system, machining system and data acquisition system. In the ultrasonic vibration system, the ultrasonic generator could be controlled to switch between ultrasonic vibration-assisted machining and conventional machining. During experiments, the vibration frequency was $30 \mathrm{kHz}$, the vibration amplitude was $4 \mu \mathrm{m}$. The detailed cutting temperature model validating were listed in Table 3 , the effect of cutting parameters on machined surface temperature was designed in Table 4. Cutting temperature on the machined surface was measured using semi-thermocouple and temperature below the machined surface was measured by K-type thermocouple. Distance from machined surface of thermocouple (DMST) is set to be $0.1 \mathrm{~mm}$ and $0.2 \mathrm{~mm}$.

Table 3

Experimental parameters for cutting temperature model validating

\begin{tabular}{|lllllll|}
\hline No. & Cutting speed $v(\mathrm{~m} / \mathrm{min})$ & $\begin{array}{l}\text { Feed rate } \\
\boldsymbol{f}_{\mathbf{z}}(\mathrm{mm} / \mathbf{z})\end{array}$ & $\begin{array}{l}\text { Cutting depth } \\
\boldsymbol{a}_{\mathbf{p}}(\mathrm{mm})\end{array}$ & $\begin{array}{l}\text { Amplitude } \\
\boldsymbol{A}(\boldsymbol{\mu m})\end{array}$ & $\begin{array}{l}\text { Frequency } \\
\boldsymbol{f}(\mathrm{kHz})\end{array}$ & DMST $(\mathrm{mm})$ \\
\hline$\# 1$ & 20 & 0.06 & 0.8 & 4 & 30 & 0.1 \\
\hline$\# 2$ & 20 & 0.06 & 0.8 & 0 & 0 & 0.1 \\
\hline$\# 3$ & 35 & 0.04 & 0.4 & 4 & 30 & 0.2 \\
\hline$\# 5$ & 35 & 0.04 & 0.4 & 0 & 0 & 0.2 \\
\hline$\# 6$ & 15 & 0.05 & 0.5 & 4 & 30 & 0 \\
\hline$\# 8$ & 30 & 0.05 & 0.5 & 0 & 0 & 0 \\
\hline$\# 9$ & 30 & 0.05 & 0.5 & 4 & 30 & 0 \\
\hline 10 & 30 & 0.05 & 0.5 & 0 & 0 & 0 \\
\hline
\end{tabular}


Table 4

Cutting parameters for effect on machined surface temperature in UVM

\begin{tabular}{|c|c|c|c|c|c|}
\hline No. & Cutting speed $v(\mathrm{~m} / \mathrm{min})$ & $\begin{array}{l}\text { Feed rate } \\
f_{z}(\mathrm{~mm} / \mathrm{z})\end{array}$ & $\begin{array}{l}\text { Cutting depth } \\
a_{p}(\mathrm{~mm})\end{array}$ & $\begin{array}{l}\text { Amplitude } \\
A(\mu \mathrm{m})\end{array}$ & $\begin{array}{l}\text { Frequency } \\
f(\mathrm{kHz})\end{array}$ \\
\hline \#11 & 15 & \multirow[t]{3}{*}{0.05} & \multirow[t]{3}{*}{0.5} & \multirow[t]{3}{*}{4} & \multirow[t]{3}{*}{30} \\
\hline \#12 & 30 & & & & \\
\hline \#13 & 45 & & & & \\
\hline \#14 & \multirow[t]{3}{*}{30} & 0.03 & \multirow[t]{3}{*}{0.5} & \multirow[t]{3}{*}{4} & \multirow[t]{3}{*}{30} \\
\hline \#15 & & 0.05 & & & \\
\hline \#16 & & 0.07 & & & \\
\hline \#17 & \multirow[t]{3}{*}{30} & \multirow[t]{3}{*}{0.05} & 0.2 & \multirow[t]{3}{*}{4} & \multirow[t]{3}{*}{30} \\
\hline \#18 & & & 0.5 & & \\
\hline \#19 & & & 0.8 & & \\
\hline
\end{tabular}

\section{Results And Discussions}

The proposed cutting temperature model for ultrasonic vibration-assisted milling is validated by a series of experiments on in-situ $\mathrm{TiB}_{2} / 7050 \mathrm{Al}$ MMCs and the results of validation are shown in Table 5 and Fig. 7. Tests \#1 to \#4 were performed for the subsurface temperature and the machined surface temperature is measured from tests \#5 to \#10.

Table 5

The validated results of the temperature model

\begin{tabular}{|lllll|}
\hline No. & DMST $(\mathrm{mm})$ & Experimental temperature $\left({ }^{\circ} \mathrm{C}\right)$ & Predicted temperature $\left({ }^{\circ} \mathrm{C}\right)$ & Relative error $(\%)$ \\
\hline$\# 1$ & 0.1 & 34.82 & 37.29 & $7.09 \%$ \\
\hline$\# 2$ & 0.1 & 37.28 & 31.15 & $16.44 \%$ \\
\hline$\# 3$ & 0.2 & 31.98 & 36.83 & $15.17 \%$ \\
\hline$\# 4$ & 0.2 & 34.59 & 41.93 & $21.22 \%$ \\
\hline$\# 5$ & 0 & 104.74 & 116.03 & $10.78 \%$ \\
\hline$\# 7$ & 0 & 126.89 & 144.39 & $13.79 \%$ \\
\hline$\# 8$ & 0 & 149.04 & 171.77 & $15.25 \%$ \\
\hline$\# 9$ & 0 & 171.19 & 182.64 & $6.69 \%$ \\
\hline$\# 10$ & 0 & 115.82 & 132.76 & $14.63 \%$ \\
\hline
\end{tabular}


It could be seen from Table 5 and Fig. 7 that the model prediction results are in good agreement with that of experiments. The proposed model is validated to be of good reliability and accuracy with the relative errors being smaller than $17 \%$. Besides, the good agreement for conventional milling experiments, whose frequency and amplitude are set to be 0 , indicates that the developed cutting temperature model could be used for both ultrasonic vibration-assisted milling and conventional milling.

In this study, the main error source might include three parts: the simplification error of the model, cumulative error of the model and measurement error. During modeling, the cutting temperature model developed is mainly taken into consideration the influence of heat source in the primary shear zone without the heat transferring into the atmosphere, which would result in the simplification error. Besides, cutting force and heat partition ratio are obtained by analytical model, which would lead to the accumulation of model error. And the measurement error might come from the measuring instruments and observing data. But from Table 4 except for test \#4, the relative errors between proposed model and measured results range from $6.69-16.44 \%$, which are all smaller than $17 \%$, showing a good prediction agreement.

Figure 8 shows the temperature contours behind the cutting edge under different depth below the machined surface. It could be seen that the subsurface temperature field of workpiece is distributed behind the cutting edge, the maximum temperature is not located below the cutting tool nose, whose location is 0.0 point along the cutting direction. Besides, viewing from test \#1 and \#3 or test \#2 and \#4, the high temperature region is becoming far away from the cutting tool nose with the increasing of the depth below the machined surface. It indicates that the workpiece temperature of the subsurface is determined by the conduction time of shear heat source.

As shown in Fig. 9, by comparing the measured cutting temperature of UVM and CM, it could be found that the cutting temperature is reduced by about $14.55 \%$ with ultrasonic vibration. There might be two reasons for this: First, the cutting force is reduced due to the ultrasonic vibration, which would result in total energy of heat generation reducing and then cutting temperature is decreased. Second, contact between the cutting tool and the workpiece is changed by the ultrasonic vibration, which would decrease heat conduction time.

In addition, the influence of cutting parameters on the machined surface cutting temperature in UVM is shown in Fig. 10. It could be found that the cutting parameters have important effect on the cutting temperature. It was increased with the cutting speed, feed rate and cutting depth increasing under a certain vibration frequency and amplitude. And cutting speed has a maximum effect on the workpiece temperature, followed by cutting depth, and feed rate has the minimum influence on it. Besides, it could be found that temperature rising ratio decreases with cutting speed and feed rate increasing while increasing obviously with cutting depth.

\section{Conclusions}

In this paper, an analytical cutting temperature prediction model was developed for axial ultrasonic vibration assisted milling in-situ $\mathrm{TiB}_{2} / 7050 \mathrm{Al}$ composites. A set of experiments were carried out to verify the model 
with and without ultrasonic vibration. Based on the results and analysis, following conclusions could be made:

(1) The heat partition ratio was built based on the moving heat source theory, which considered the effect of ultrasonic vibration, cutting parameters, tool geometry and material properties. With verification, the proposed cutting temperature model shows a good agreement with experiments with the relative errors being smaller than $17 \%$.

(2) Under the influence of heat conduction time from shear heat source to workpiece, it was found that the subsurface temperature field of workpiece was distributed behind the cutting edge and with increasing the depth below the machined surface, the high temperature region was becoming far away from the cutting tool nose.

(3) From comparison with $\mathrm{CM}$, it was found that the cutting temperature could be significantly reduced by about $14.55 \%$ with UVM. With increasing cutting speed, feed rate and cutting depth, the cutting temperature increased accordingly. The cutting speed has the highest effect on the workpiece temperature, followed by cutting depth, and the feed rate has the minimum influence. Besides, it could be found that temperature rising ratio decreases with cutting speed and feed rate increasing while increasing obviously with cutting depth.

In the future study work, the coupling effect of force-temperature on the integrity for ultrasonic vibrationassisted machining in-situ $\mathrm{TiB}_{2} / 7050 \mathrm{Al}$ composites.

\section{Declarations}

\section{Acknowledgements}

This work is sponsored by National Natural Science Foundation of China (Grant No. 51775443), National Science and Technology Major Project (Grant No. 2017-VII-0015-0111), China Postdoctoral Science Foundation (Grant No. 2020M683569).

\section{Author contribution}

Xiaofen Liu: Writing, modeling, methodology, investigation, calculating, and analysis. Wenhu Wang: materials and equipment support, Ruisong Jiang: Investigation. Kunyang Lin: Checking, Junchen Li: Calculation, Chenwei Shan: Funding acquisition.

\section{Data availability}

All authors confirm that the data supporting the findings of this study are available within the article.

\section{Code availability}

Not applicable.

\section{Ethics approval}


The manuscript has not been submitted to any other journal for simultaneous consideration. The submitted work is original and has not been published elsewhere in any form or language.

\section{Consent to participate}

All authors voluntarily agree to participate in this research study.

\section{Consent for publication}

All authors voluntarily agree to publish in this research study.

\section{Conflict of interest}

The authors declare that they have no conflict of interest.

\section{References}

1. Nath C, Rahman M (2008) Effect of machining parameters in ultrasonic vibration cutting. Int $J$ Mach Tools Manuf 48(9):965-974

2. Shen $\mathrm{XH}$, Zhang JH, Li H, Wang JJ, Wang XC (2012) Ultrasonic vibration-assisted milling of aluminum alloy. The International Journal of Advanced Manufacturing Technology 63(1-4):41-49

3. Liu J, Chen G, Ren CZ, Qin XD, Zou YH, Ge JY (2020) Effects of axial and longitudinal-torsional vibration on fiber removal in ultrasonic vibration helical milling of CFRP composites. Journal of Manufacturing Processes 58:868-883

4. Ibrahim MR, Rahim Z, Rahim E, Tobi L, Cheng K, Ding H. An Experimental Investigation of Cutting Temperature and Tool Wear in 2 Dimensional Ultrasonic Vibrations Assisted Micro-Milling. Proceedings paper, 3rd International Conference on Mechatronics and Mechanical Engineering. OCT21-23, 2016

5. Shen XH, Zhang JH, Xing DL, Zhao YF (2012) A study of surface roughness variation in ultrasonic vibration-assisted milling. The International Journal of Advanced Manufacturing Technology 58(58):553-561

6. Ni CB, Zhu LD, Liu CF, Yang ZC (2018) Analytical modeling of tool-workpiece contact rate and experimental study in ultrasonic vibration-assisted milling of Ti-6Al-4V. Int J Mech Sci 142:97-111

7. Li Z, Zhang DY, Jiang XG, Qin W, Geng DX (2017) Study on rotary ultrasonic-assisted drilling of titanium alloys (Ti6Al4V) using 8-facet drill under no cooling condition. The International Journal of Advanced Manufacturing Technology 90(9-12):3249-3264

8. Geng DX, Lu ZH, Yao G, Liu JJ, Li Z, Zhang DY (2017) Cutting temperature and resulting influence on machining performance in rotary ultrasonic elliptical machining of thick CFRP. Int $J$ Mach Tools Manuf 123:160-170

9. Cong WL, Zou XT, Deines TW, Wu N, Wang XW, Pei ZJ (2012) Rotary ultrasonic machining of carbon fiber reinforced plastic composites: An experimental study on cutting temperature. J Reinf Plast Compos 31(22):1516-1525

10. Pálmai Z (1987) Cutting temperature in intermittent cutting. Int J Mach Tools Manuf 27(2):261-274 
11. Kountanya R (2008) Cutting tool temperatures in interrupted cutting-The effect of feed-direction modulation. Journal of Manufaturing Processes 10(2):47-55

12. Shi WT, Hou YJ, Kong C, Liu YD. Optimization of cutting force and temperature during Ti6Al4V/AI7050 laminate composites elliptical vibration turning. Proceedings of the Institution of Mechnical Engineers, Part C: J Mechanical Engineering Science. 2019, 233 (16): 5585-5596

13. Mitrofanov AV, Babitsky VI, Silberschmidt VV (2004) Finite element analysis of ultrasonically assisted turning of Inconel 718. Journal of Material Processing Technology 153-154:233-239

14. Mitrofanov AV, Babitsky VI, Silberschmidt VV (2005) Thermomechanical finite element simulations of ultrasonically assisted turning. Comput Mater Sci 32(3-4):463-471

15. Ahmed N, Mitrofanov AV, Babitsky VI, Silberschmidt VV (2007) Analysis of forces in ultrasonically assisted turning. J Sound Vib 308(3-5):845-854

16. Muhammad R, Maurotto A, DemiralM RA, Silberschmidt V (2014) Thermally enhanced ultrasonically assisted machining of Ti alloy. CIRP J Manufact Sci Technol 7(2):159-167

17. Patil S, Joshi S, Tewari A, Joshi SS (2014) Modelling and simulation of effect of ultrasonic vibrations on machining of Ti6Al4V [J]. Ultrasonics 54(2):694-705

18. Khajehzadeh M, Razfar MR. Theoretical modeling of tool mean temperature during ultrasonically assisted turning. Proceedings of the Institution of Mechnical Engineers, Part B: Journal of Engineering Manufacture. 2016, 230 (4): 675-693

19. Verma GC, Pandey PM, Dixit US (2018) Estimation of workpiece-temperature during ultrasonic-vibration assisted milling considering acoustic softening. Int J Mech Sci 140:547-556

20. Chen JB, Xu MH, Xie C, Du JK, Dai HF, Fang QH (2018) A nonuniform moving heat source model for temperature simulation in ultrasonic-assisted cutting of titanium alloys. The International Journal of Advanced Manufacturing Technology 97(5-8):3009-3021

21. Liu XF, Wang WH, Jiang RS, Xiong YF, Lin KY (2020) Tool wear mechanisms in axial ultrasonic vibration assisted milling in-situ $\mathrm{TiB}_{2} / 7050 \mathrm{Al}$ metal matrix composites. Advances in Manufacturing 8(2):252-264

22. Liu XF, Wang WH, Jiang RS, Xiong YF, Lin KY, Li JC (2020) Investigation on surface roughness in axial ultrasonic vibration-assisted milling of in situ $\mathrm{TiB}_{2} / 7050 \mathrm{Al}$ MMCs. The International Journal of Advanced Manufacturing Technology 111(1-2):63-75

23. Jiang RS, Wang WH, Song GD, Wang ZQ (2016) Experimental investigation on machinability of in situ formed $\mathrm{TiB}_{2}$ particles reinforced Al MMCs. Journal of Manufacturing Processes 23:249-257

24. Xiong YF, Wang WH, Shi YY, Jiang RS, Lin KY, Song GD, Shao MW, Liu XF, Li JC, Shan CW (2021) Machining performance of in-situ $\mathrm{TiB}_{2}$ particle reinforced Al-based metal matrix composites: A literature review. Journal of Advanced Manufacturing Science Technology 1(2)2021003):1-21

25. Liu XF, Wang WH, Jiang RS, Xiong YF, Lin KY, Li JC, Shan CW (2020) Analytical model of cutting force in axial ultrasonic vibration-assisted milling in-situ TiB 2 /7050Al PRMMCs. Chin J Aeronaut 34(4):160-173

26. Verma GC, Pandey PM, Dixit US (2018) Modeling of static machining force in axial ultrasonic-vibration assisted milling considering acoustic softening. Int J Mech Sci 136:1-16 
27. Lazoglu I, Altintas Y (2002) Prediction of tool and chip temperature in continuous and interrupted machining. Int J Mach Tools Manuf 42(9):1011-1022

28. Shaw MC, Cookson JO (2005) Metal cutting principles. Oxford University Press, New York

29. Komanduri R, Hou ZB (2000) Thermal modeling of the metal cutting process: Part I-Temperature rise distribution due to shear plane heat source. Int J Mech Sci 42(9):1715-1752

30. Xiong YF, Wang WH, Jiang RS, Lin KY (2018) Analytical model of workpiece temperature in end milling insitu $\mathrm{TiB}_{2} / 7050 \mathrm{Al}$ metal matrix composites. Int J Mech Sci 149:285-297

31. Shan CW, Zhang X, Shen B, Zhang DH (2019) An improved analytical model of cutting temperature on orthogonal cutting of Ti6Al4V. Chin J Aeronaut 32(3):759-769

32. Kumabe J (1985) Precision machining foundation and application of vibration cutting. China Machine Press, Beijing

33. Blok H. Theoretical study of temperature rise at surfaces of actual contact under oiliness lubricating conditions. Proceeding of General Discussion on Lubrication and Lubricants, Institute of Mechanical Engineers London, 1938, p. 22-235

\section{Figures}

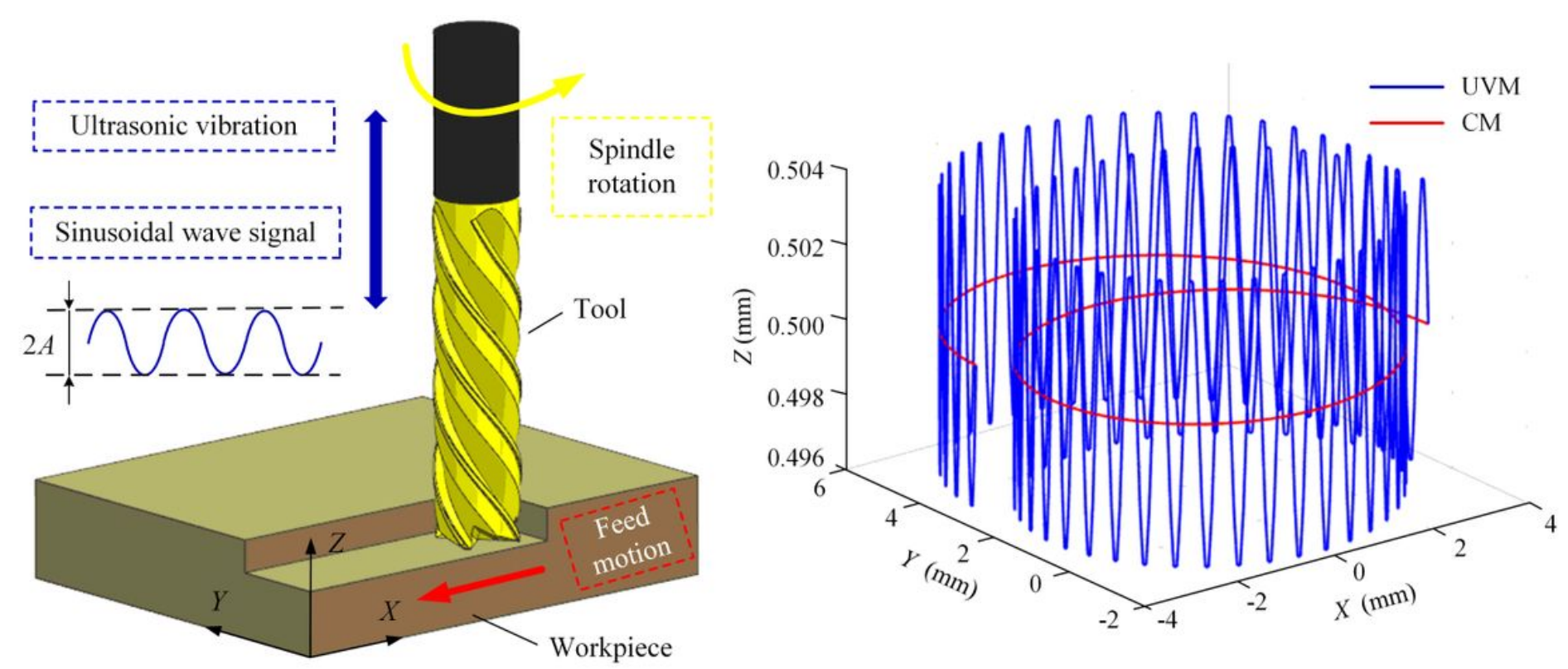

Figure 1

Kinematic characteristics of axial UVM process (a) Motion of cutting tool in UVM (b) Motion trajectory of one tooth in UVM and CM 


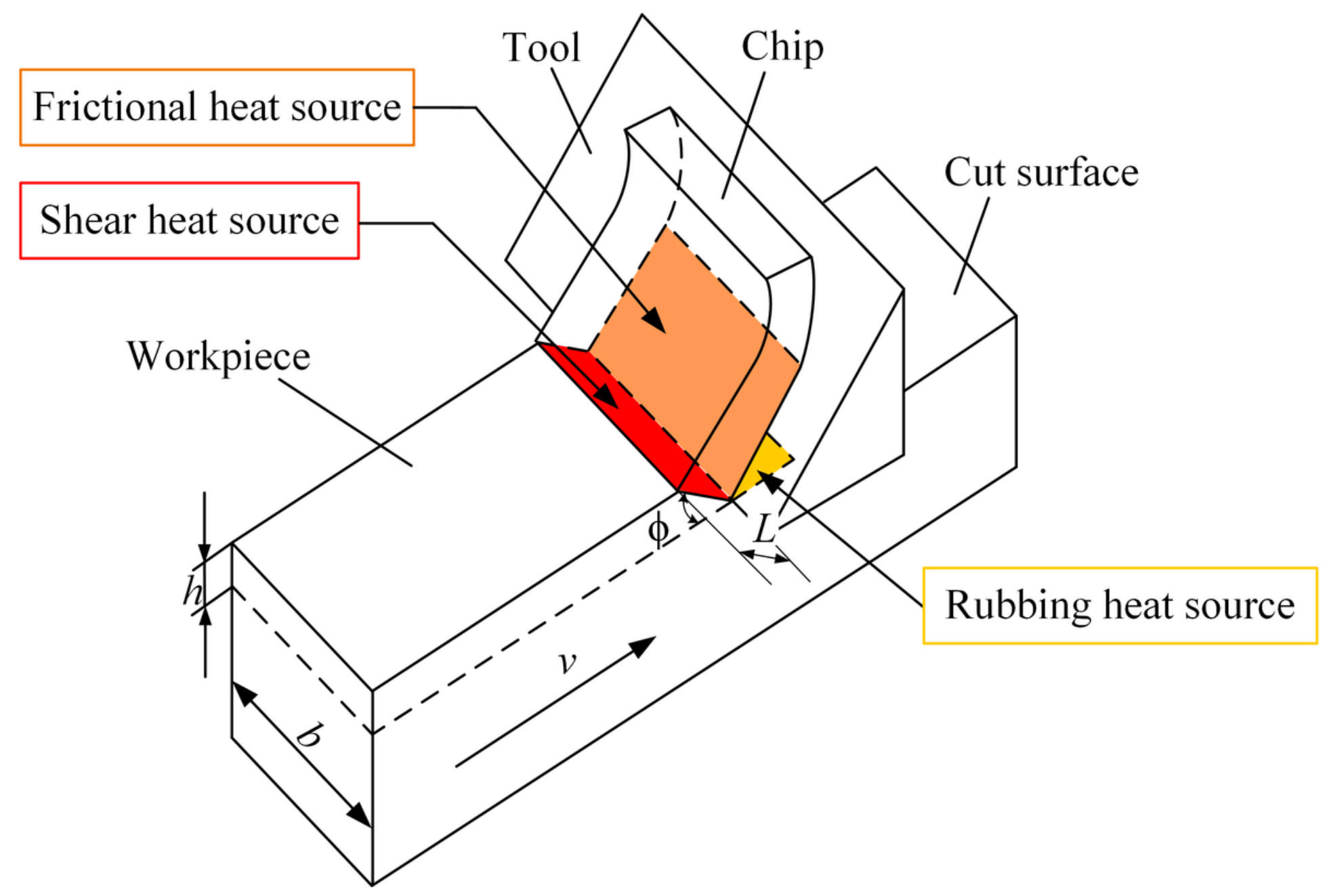

Figure 2

Schematic of heat sources in orthogonal cutting process

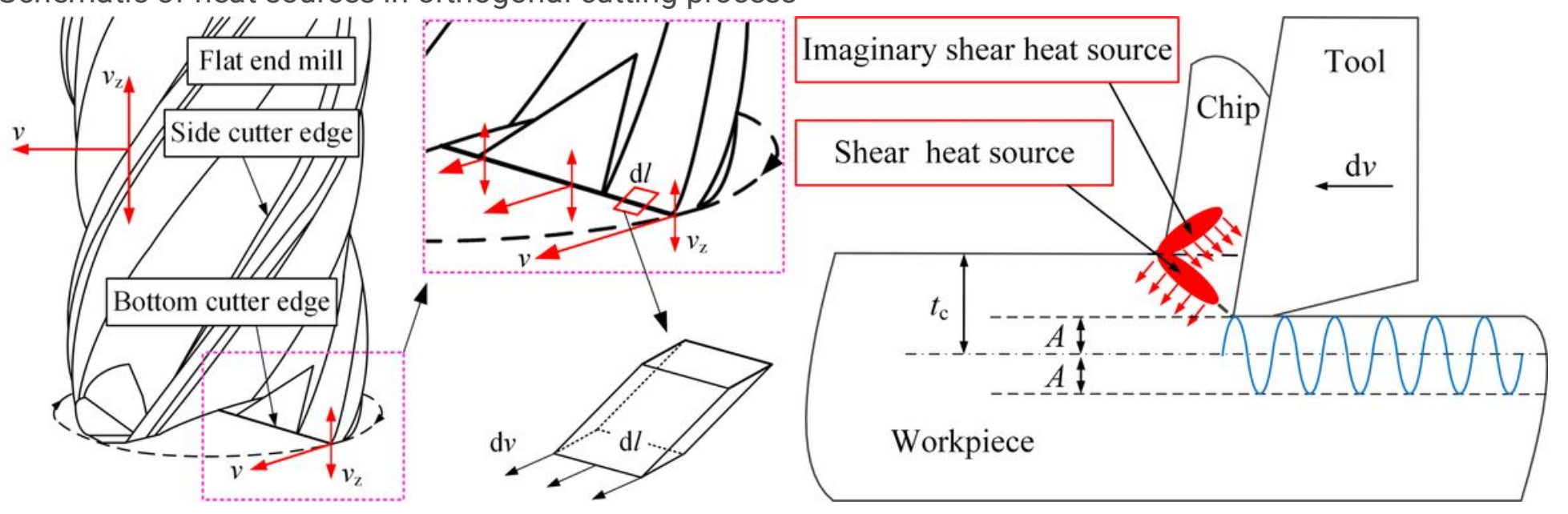

Figure 3

Heat source of 2D orthogonal cutting process (a) Discretization of the bottom cutting edge (b) Heat source of orthogonal cutting 


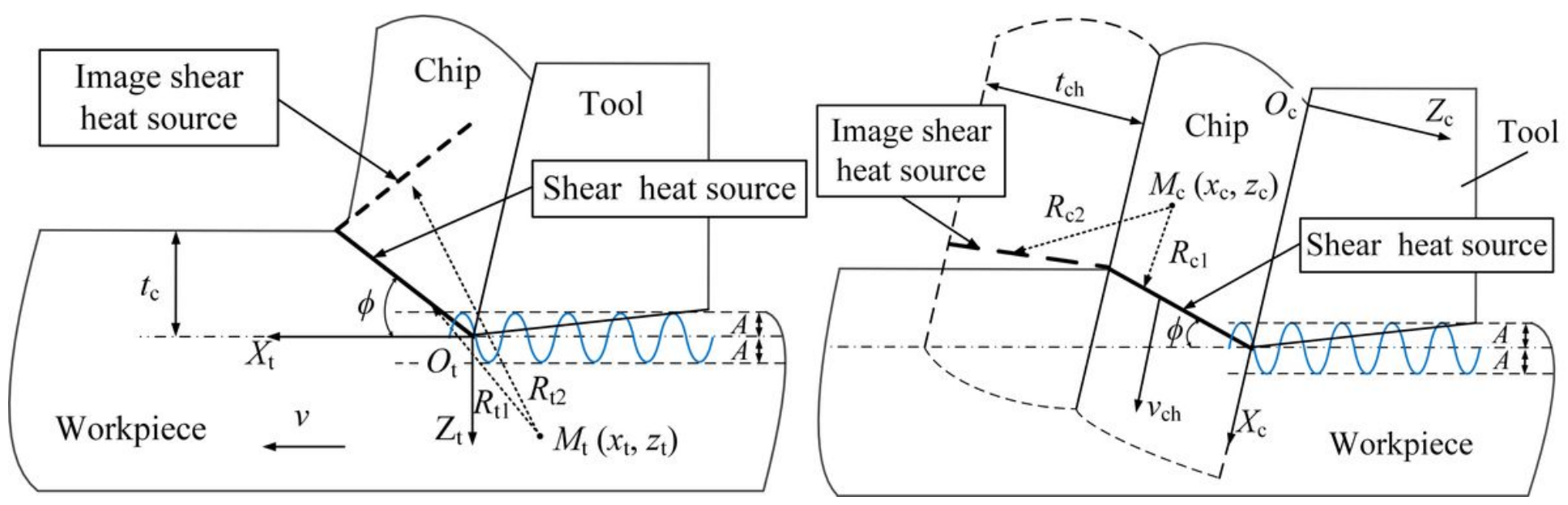

\section{Figure 4}

Schematic of temperature modeling (a) Heat source and image for the workpiece side (b) Heat source and image for the chip side

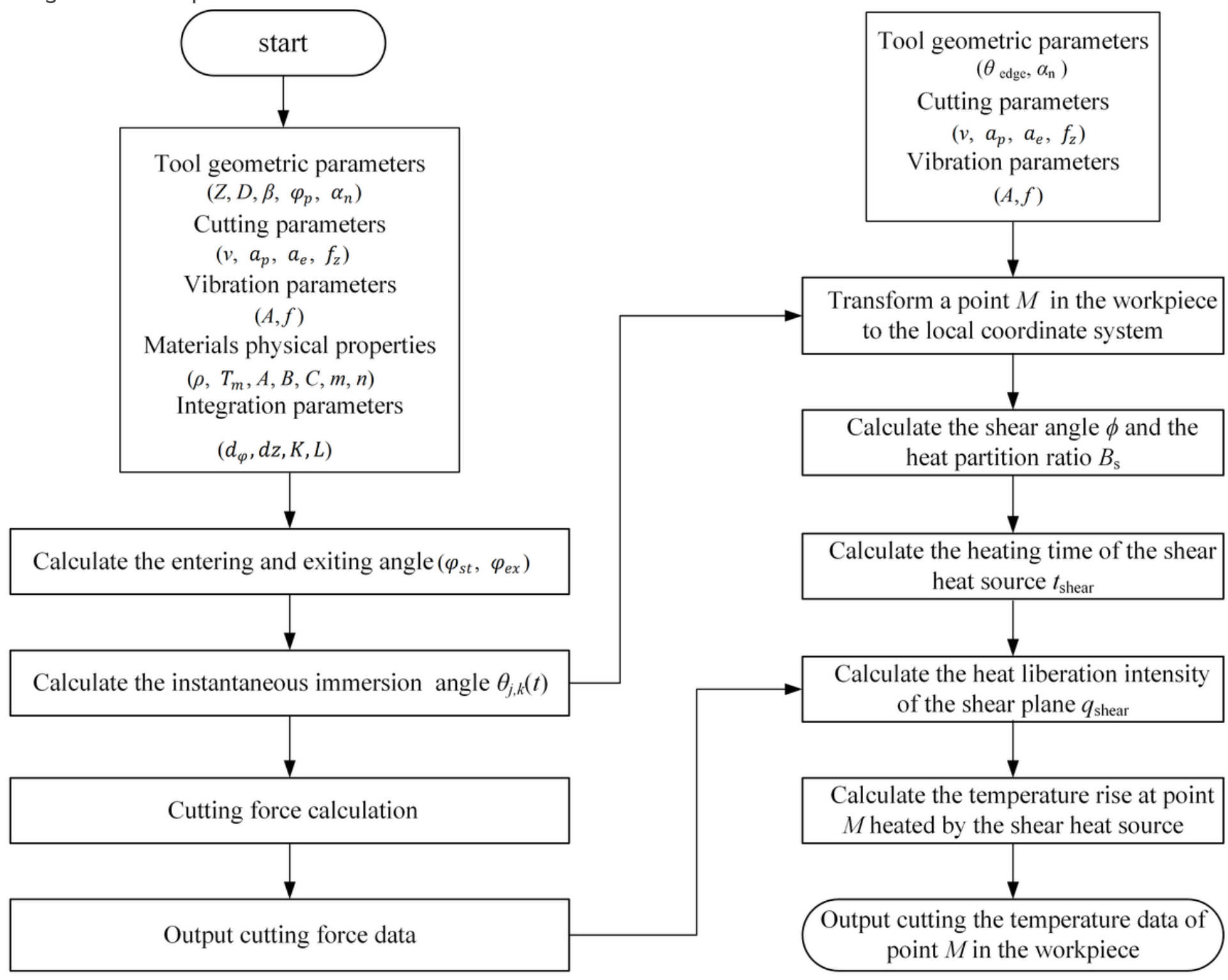

Figure 5 
The flowchart of cutting temperature calculation

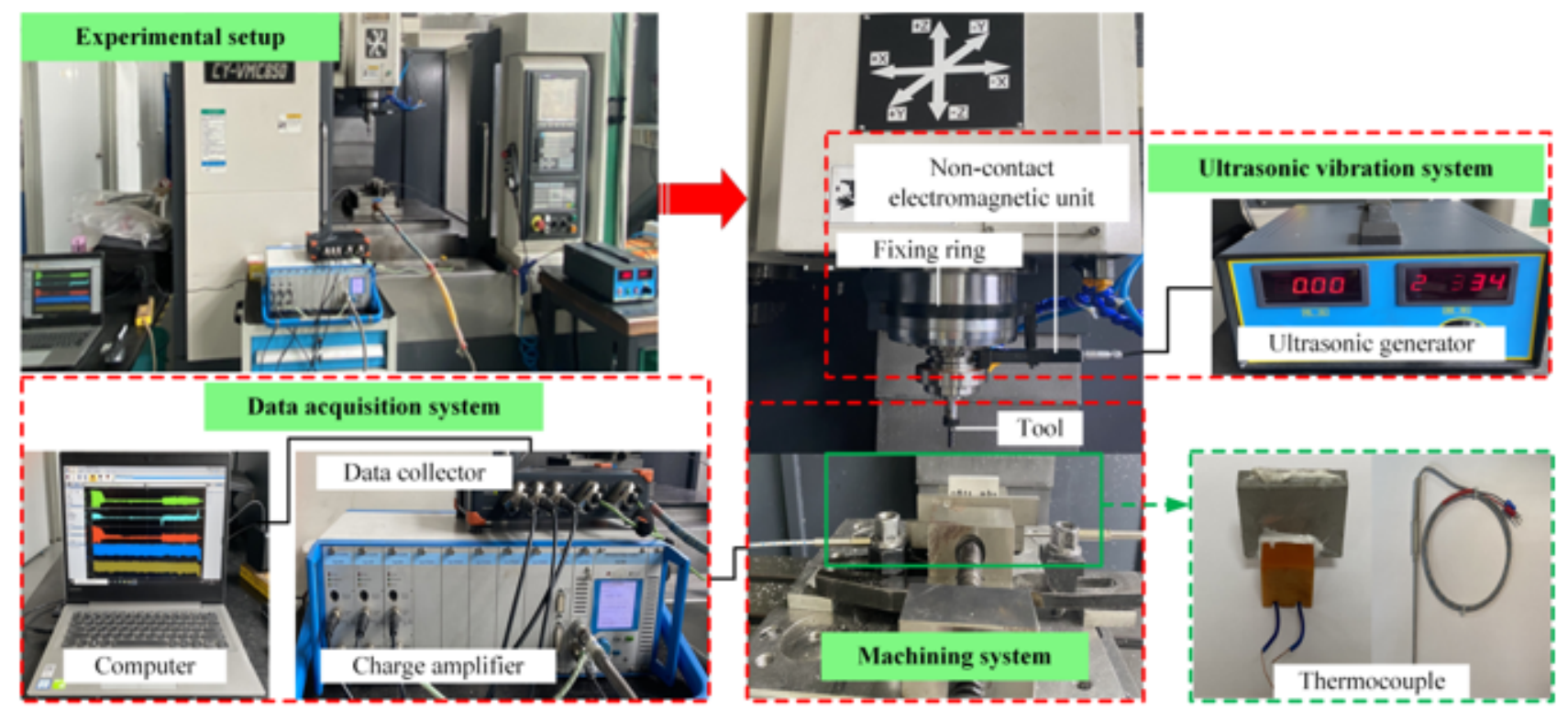

\section{Figure 6}

Schematic diagram of experimental setup

Test number

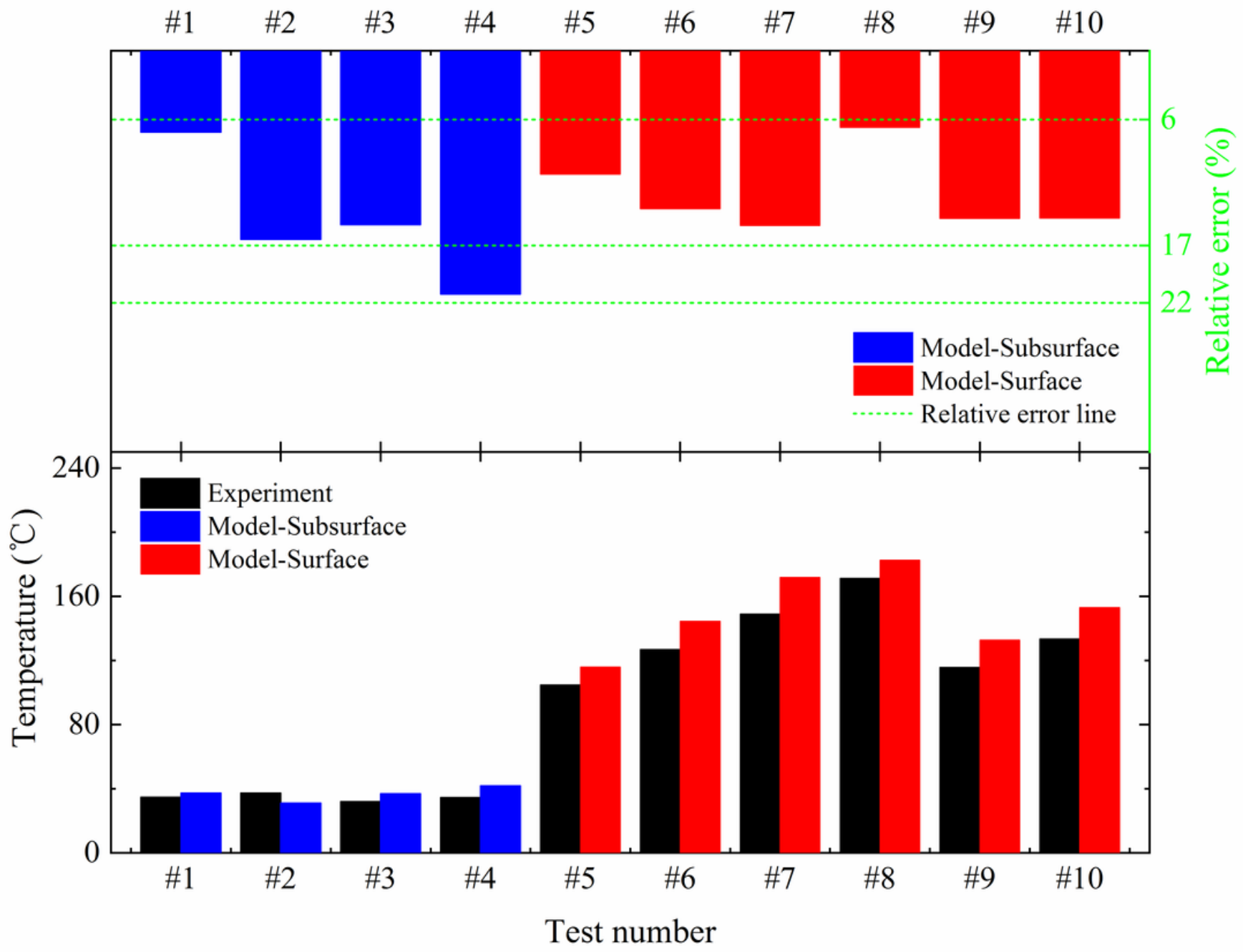


Figure 7

Relative error between the predicted and experimental cutting temperature

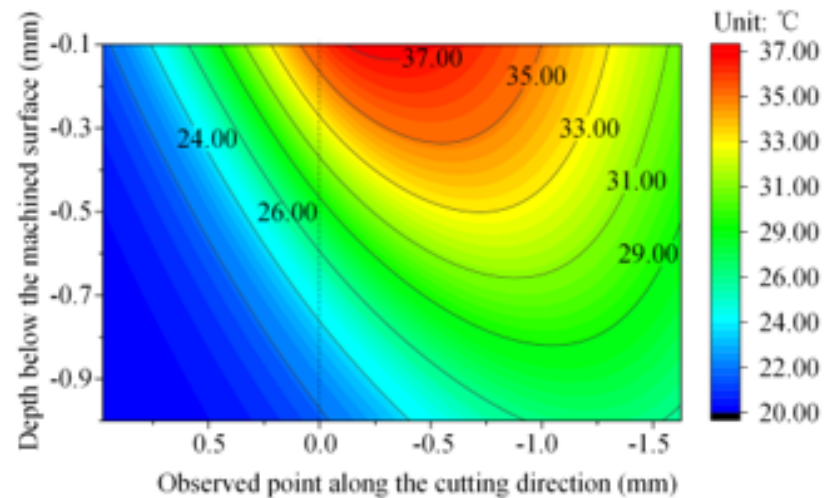

(a) Test \#1

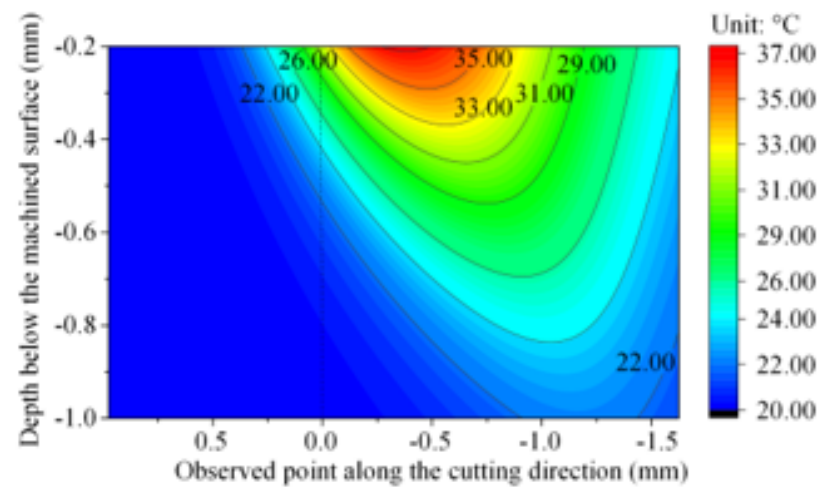

(c) Test \#3

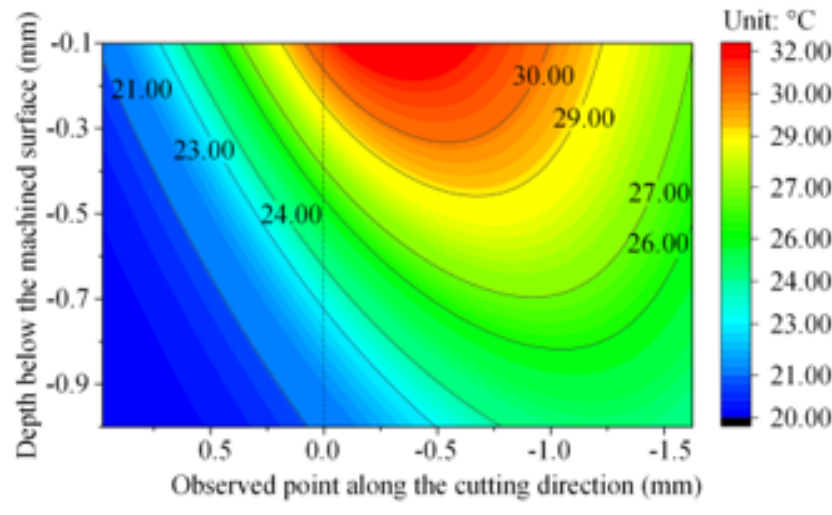

(b) Test $\# 2$

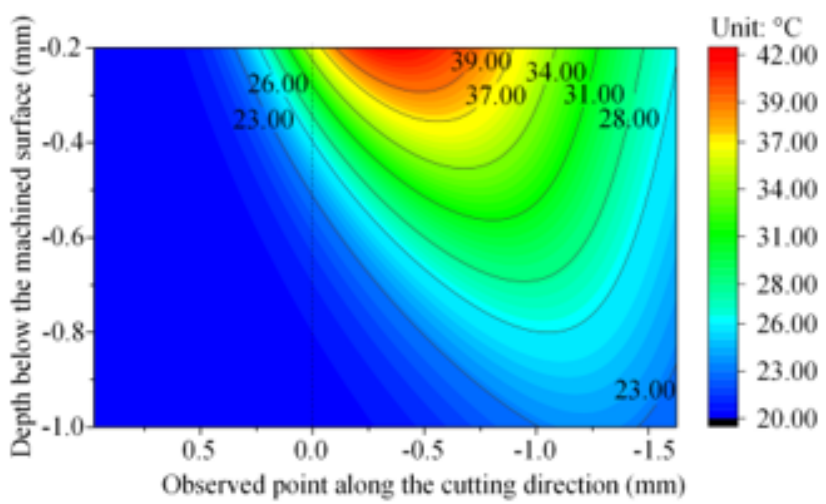

(d) Test \#4

\section{Figure 8}

Temperature contours at different depth below the machined surface 


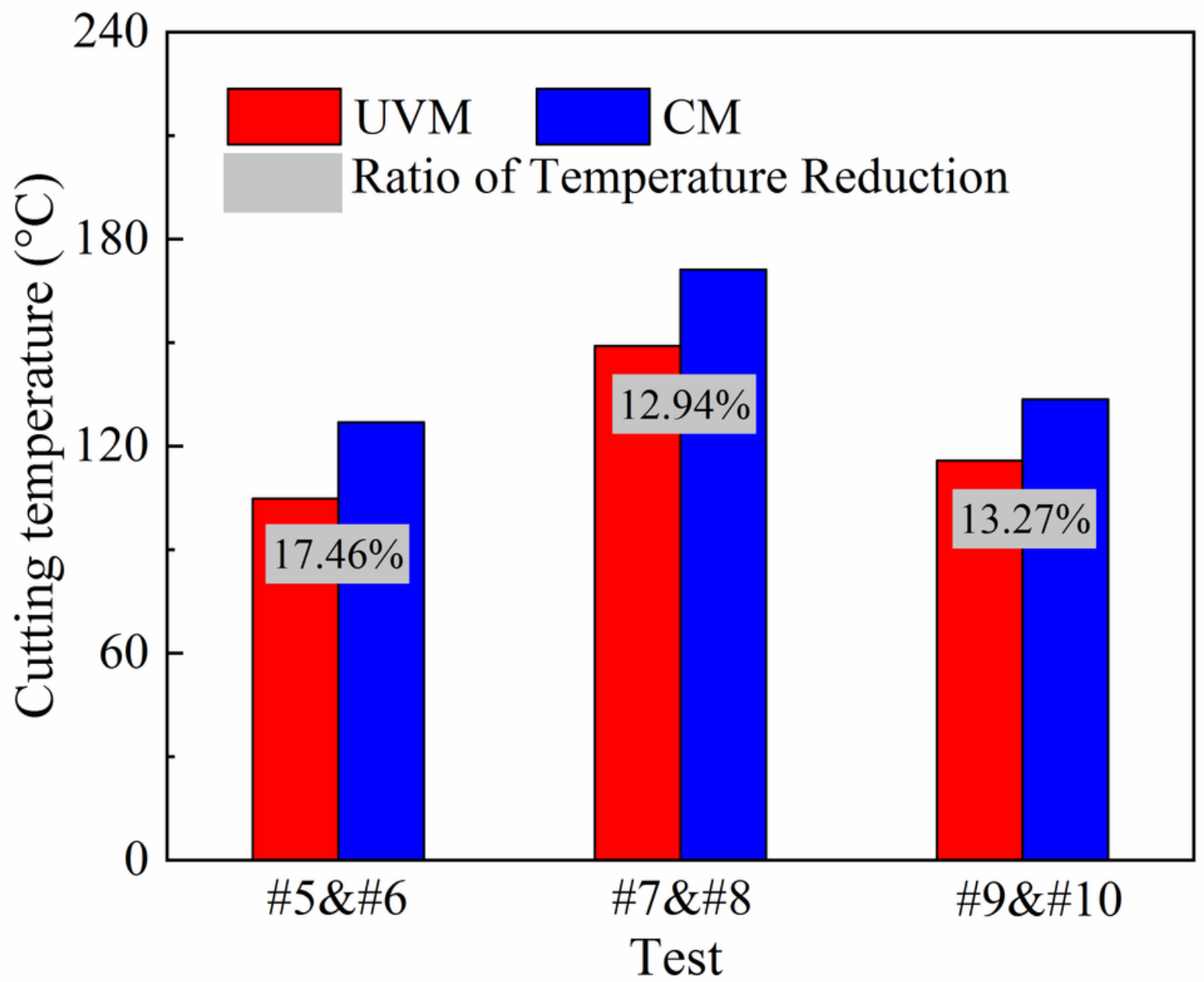

Figure 9

Comparison of the cutting temperature between UVM and CM 


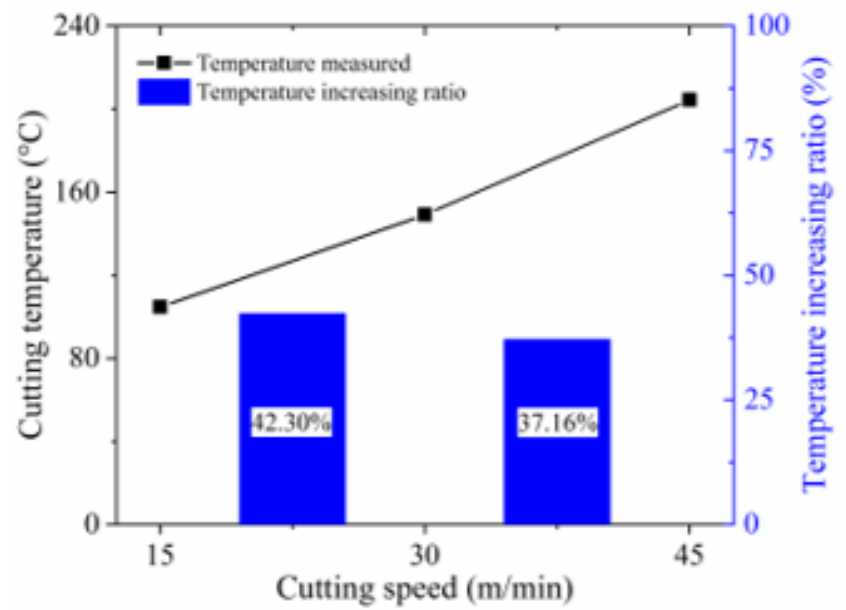

(a) $f_{\mathrm{z}}=0.05 \mathrm{~mm} / \mathrm{z}, a_{\mathrm{p}}=0.5 \mathrm{~mm}, f=30 \mathrm{kHz}, A=4 \mu \mathrm{m}$

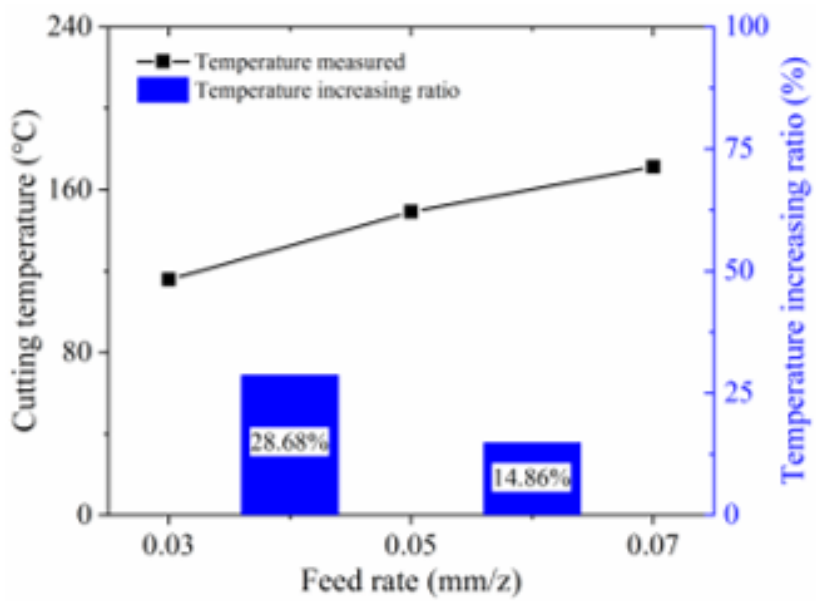

(b) $v=30 \mathrm{~m} / \mathrm{min}, a_{\mathrm{p}}=0.5 \mathrm{~mm}, f=30 \mathrm{kHz}, A=4 \mu \mathrm{m}$

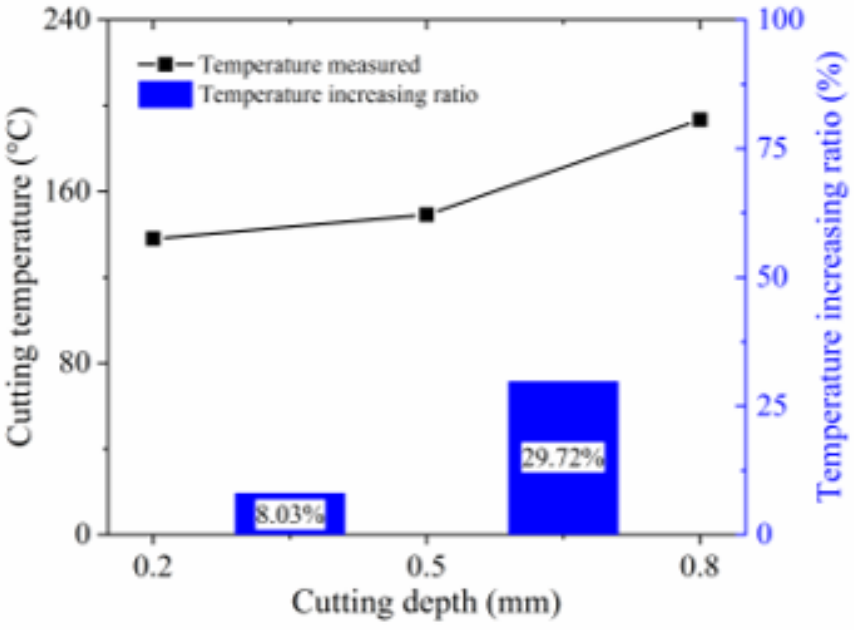

(c) $v=30 \mathrm{~m} / \mathrm{min}, f_{2}=0.05 \mathrm{~mm} / z, f=30 \mathrm{kHz}, A=4 \mu \mathrm{m}$

\section{Figure 10}

The effect of cutting parameters on cutting temperature in UVM 